\title{
The influence of humidity on the ablation of continental-type glaciers
}

\author{
Hiroyuki Ohno, Tetsuo Ohata and Keiji Higuchi \\ Water Research Institute, Nagoya University, Nagoya 404-01, Japan
}

\begin{abstract}
The annual evaporation of a continental-type glacier $\left(43^{\circ} 05^{\prime} \mathrm{N}\right.$, $86^{\circ} 48^{\prime} \mathrm{E}$ ) in the Chinese Tien Shan is estimated, based on data derived from four field observations carried out between summer 1987 and spring 1988, and data from a permanent weather station near the glacier. The evaporation during the melting and non-melting seasons is estimated as $81 \mathrm{~mm}$ and negligible, respectively. Assuming that the ablation is equivalent to the annual precipitation $(650 \mathrm{~mm})$ in 1987 , estimated annual evaporation of $81 \mathrm{~mm}$ is $12 \%$ of the ablation and consumes $54 \%$ of the energy which causes the ablation. It can be said that evaporation suppresses ablation by $50 \%$ in comparison with the condition in which there is no evaporation.

The influence of fluctuations of air temperature and humidity on the ablation of the glacier were evaluated. Changes in temperature and humidity cause larger changes in ablation of glaciers in a cold and dry climate. The influence of humidity change is very important to glaciers located in a relatively warm environment.
\end{abstract}

\section{INTRODUCTION}

Glaciers in high mountains located in inner-continental arid areas are called "continental-type glaciers" and play an important role as water resources for irrigation in surrounding dry lands. In general, because of the aridity of the environment, the term of latent heat by evaporation occupies a relatively large percentage of the summer heat balance on the surface of these glaciers. Chinese scientists named them "continental-type glaciers". Kou and others (1982) proposed, as a criterion of continentaltype glaciers, those in which summer heat loss by evaporation occupies more than $15 \%$. Some previous studies on energy or mass balance (e.g. Shi and Xie, 1964; Kaser, 1986; Ohno, 1989; Ohmura and others, 1990) stress the possibility that the process of evaporation plays an important role in suppressing summer ablation, because required heat by sublimation of ice is about eight times as large as that by fusion. On the other hand, considering that the climate over a continental glacier in winter has extremely low vapour pressure and prevailing fine weather, ablation caused by evaporation (sublimation) may occur to some extent, although previous studies on snow covers in relatively humid places in non-melting seasons concluded that the ablation or accumulation caused by sublimation is negligible (Kojima and others, 1985; Lemmelä and Kuusisto, 1974). Nevertheless, our present knowledge of evaporation (or sublimation) from the glaciers or the snow cover is only fragmentary, and was carried out during the melting season (e.g. Croft, 1944; Xie and Cao, 1960; Beaty, 1975; Takahashi and others, 1989).

For the purpose of evaluating the influence of the process of evaporation on a glacier, it is desirable to investigate not only the amount of evaporation in the melting season but also that during the non-melting season, and their relationships with the climatological elements. This paper evaluates the influence of evaporation on ablation of continental-type glaciers through estimating the annual evaporation of such a glacier in the Tien Shan mountains, China, based on the results of field observations and daily meteorological data. Further, the influence of evaporation on mass balance is evaluated. The possible response of glaciers to climatic change is also estimated.

\section{FIELD OBSERVATION AND DATA}

Field observations were carred out at a site $4010 \mathrm{~m}$ a.s.l. in the accumulation area of Glacier No. $1\left(43^{\circ} 05^{\prime} \mathrm{N}\right.$, $86^{\circ} 48^{\prime} \mathrm{E}$ ), at the headwater of the Urümqi River, Tien Shan, China. The study area is shown in Figure 1. Observations were made from 12 to 29 July 1987, from 15 to 23 August 1987 (summer observation), from 11 October to 8 November 1987 (autumn observation), from 23 January to 9 February 1988 (winter observation), and from 6 to 22 April 1988 (spring observation). The observation point is covered with firn all the year round. The meteorological elements such as air temperature, relative humidity, wind speed and net radiation were measured continuously and averaged for a 30-minute period. The evaporation rates were measured directly by weighing the snow masses in aluminium containers (four to six in number, $5 \mathrm{~cm}$ in depth and $242 \mathrm{~cm}^{2}$ in surface area). The elements observed and the instruments used 


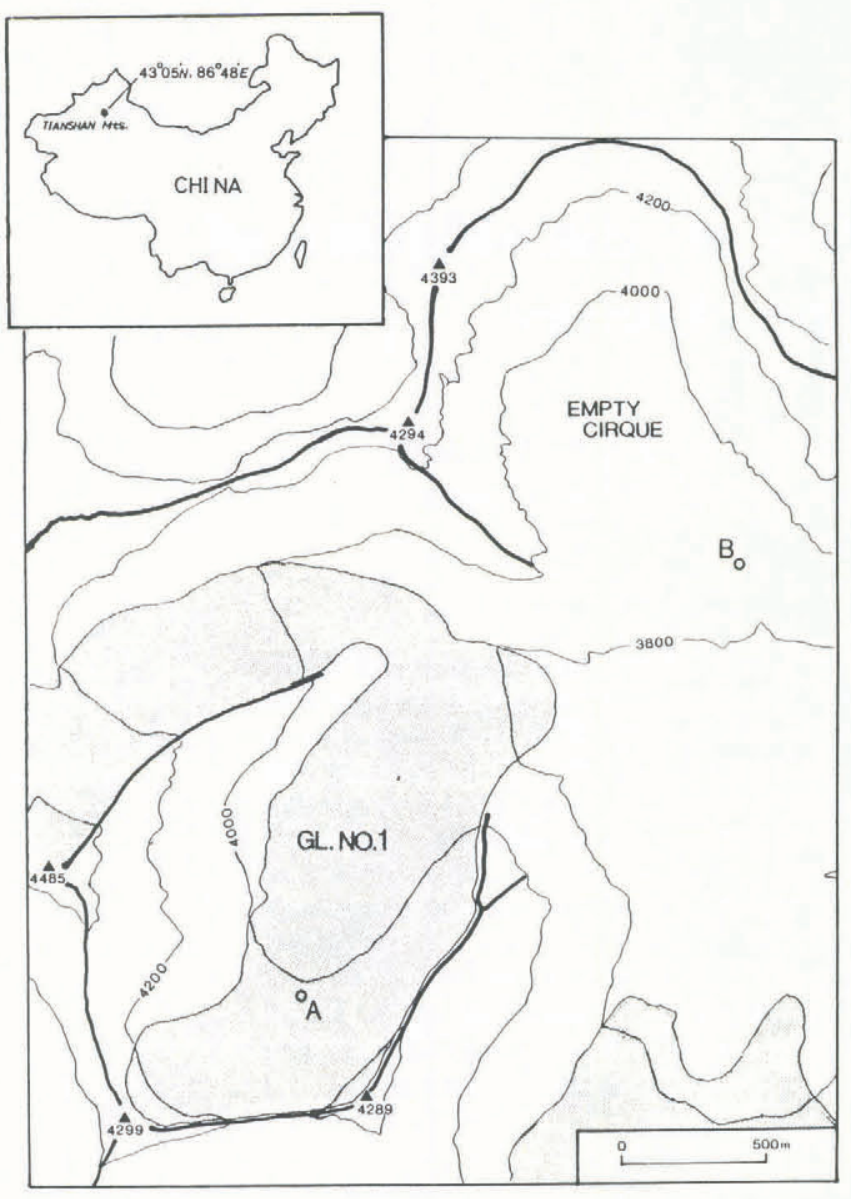

Fig. 1. Map of the study area. The hatched area indicates glaciers. Observations were made at a site which is indicated with a circle with $A$.

were summarized in a data report (Ohno, 1988). Additional data used in this study were the daily meteorological observations from 1 June 1987 to 31 May 1988 that were made at the weather station $(3540 \mathrm{~m}$ a.s.l.) which is located $2 \mathrm{~km}$ east of the glacier.

Swiss scientists made an independent field study at the equilibrium line altitude on this glacier during summers 1986 and 1987, and have published a research report (Ohmura and others, 1990).

\section{VAPOUR FLUX ON THE GLACIER}

As the surface temperature and the surface specific humidity are constant on a melting glacier, the water vapour flux can be estimated using the bulk transfer method with information about the temperature, humidity and wind speed in the atmospheric boundary layer. It is, however, not possible to apply this method for glaciers under non-melting conditions because surface elements vary widely according to the condition of surface heat balance. Therefore, it is convenient when calculating annual evaporation to divide the year into two seasons: the melting season in which the firn is melting during most of the day and the non-melting season during which melting never occurs. Figure 2 shows the air temperature and atmospheric water-vapour pressure at the weather station from June 1987 to May 1988. As the air

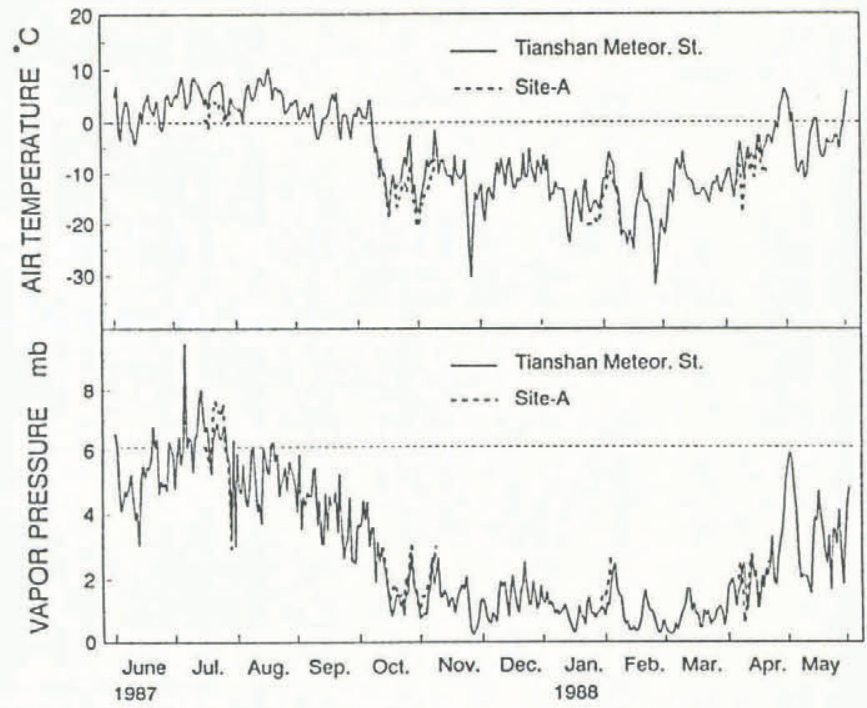

Fig. 2. Annual trend of atmospheric vapour pressure observed at the weather station ( $3540 \mathrm{~m}$ a.s.l., $2 \mathrm{~km}$ east of Glacier No. 1) indicated by a solid line and at site $A$ (4010 $m$ a.s.l.) with a dashed line. The saturation vapour pressure for $0^{\circ} \mathrm{C}(6.11 \mathrm{mbar})$ is indicated by a fine dashed line.

temperature at the weather station was higher than that at the measurement site, by $3.0^{\circ} \mathrm{C}$ on average, the air temperature at the measurement site was above $-3^{\circ} \mathrm{C}$ most days during the period from June to September. According to Ageta and others (1980), who suggest that a mountain glacier in Nepal begins to melt when the air temperature exceeds $-3^{\circ} \mathrm{C}$, a melting season from 1 June to 30 September 1987 and a non-melting season from 1 October 1987 to 31 May 1988 are assumed in this study.

\section{MELTING SEASON}

In order to determine the vapour flux, the lysimeter method and bulk estimation are applied for the melting season.

Snow in the containers was weighed to a resolution of $0.1 \mathrm{~g}$ about every two hours. When the snow melted quickly or when precipitating clouds were approaching, this time interval was shortened. The snow was not weighed during the night. The bulk method was applied to the gradient of specific humidity calculated from the measured temperature at the height of $1.5 \mathrm{~m}$ above the surface and at the surface. The surface specific humidity was calculated on the assumption that the water vapour is at saturation on the surface. The wind speed was measured only at one height $(1.8 \mathrm{~m})$. As the condition of the firn in the accumulation area on this glacier is smooth, the roughness length of $1 \mathrm{~mm}$ is assumed in this study. This value is slighly smaller than the roughness lengths reported by Moore (1983) and Munro (1989).

The vapour flux $E$ was calculated by the following formula with friction velocity $u_{*}$ and friction specific humidity $q_{*}$

$$
E=\rho u_{*} q_{*},
$$

where $\rho$ is density of the air. The bulk coefficient is 
defined by the formula

$$
E=\rho \mathrm{C}_{\mathrm{E}} U\left(q_{\mathrm{a}}-q_{\mathrm{s}}\right),
$$

where $U$ us the wind speed at height $z_{\mathrm{u}}$ above the surface and $\left(q_{\mathrm{a}}-q_{\mathrm{s}}\right)$ is the difference of specific humidity between height $\mathrm{z}_{\mathrm{q}}$ and the surface. In the log-linear approximation, which is often applied in the stable atmospheric condition (Munro, 1989; Hay and Fitzharris, 1988), $u_{*}$ and $q_{*}$ are estimated from

$$
u_{*}=\frac{\kappa U}{\ln \left(\frac{\mathrm{z}_{\mathrm{u}}}{\mathrm{z}_{0}}+\frac{\alpha \mathrm{z}_{\mathrm{m}}}{L}\right)},
$$

and

$$
q_{*}=\frac{\kappa\left(q_{\mathrm{a}}-q_{\mathrm{s}}\right)}{\ln \left(\frac{\mathrm{z}_{\mathrm{q}}}{\mathrm{z}_{\mathrm{E}}}+\frac{\alpha \mathrm{z}_{\mathrm{q}}}{L}\right)}
$$

where $\kappa$ is the von Kármán constant, and $\mathrm{z}_{0}$ and $\mathrm{z}_{\mathrm{E}}$ are the roughness lengths for wind and water vapour, respectively. $\alpha$ is the empirical constant which reflects the sensitivity of the air to the stability change and is characterized by Monin-Obukhov length scale $L$

$$
L=\frac{u_{*}^{3} T}{\kappa \mathrm{g} Q},
$$

where $T$ is the absolute temperature of the air and $g$ is the gravitational acceleration. $Q$ is the temperature flux

$$
Q=U_{*} T_{*},
$$

where $T_{*}$ is the friction temperature. Dyer (1974) reported the parameter of $\alpha$ as 5, and Munro and Davies (1978) derived the value of 4.5 from their observations on a glacier.

This approximation is not suitable for this study because the surface temperature on the glacier frequently becomes higher than the air temperature during the nonmelting season. The log-linear approximation requires another $\alpha$ for the unstable atmospheric conditon and has a narrower applicable range in the unstable region (up to $-0.1 \approx \mathrm{Ri}$; Takeuchi and Kondo, 1981). Therefore, profiles are estimated in a form of the integrated universal functions of momentum $\phi_{\mathrm{m}}$, temperature $\phi_{\mathrm{h}}$ and water vapour $\phi_{\mathrm{e}}$. In this approximation, $u_{*}$ and $q_{*}$ are estimated:

$$
u_{*}=\frac{\kappa U}{\int_{\zeta_{\mathrm{m}_{1}}}^{\zeta_{\mathrm{m}_{2}}} \frac{\phi_{\mathrm{m}}}{\zeta} \mathrm{d} \zeta}, \quad \text { where }\left\{\begin{array}{l}
\zeta_{\mathrm{m}_{2}}=\mathrm{z}_{u} / L \\
\zeta_{\mathrm{m}_{1}}=\mathrm{z}_{0} / L
\end{array},\right.
$$

and

$$
q_{*}=\frac{\kappa\left(q_{\mathrm{a}}-q_{\mathrm{s}}\right)}{\int_{\zeta_{\mathrm{e}_{1}}}^{\zeta_{\mathrm{e}_{2}}} \frac{\phi_{\mathrm{e}}}{\zeta} \mathrm{d} \zeta}, \quad \text { where } \quad\left\{\begin{array}{l}
\zeta_{\mathrm{e}_{2}}=\mathrm{z}_{q} / L \\
\zeta_{\mathrm{e}_{1}}=\mathrm{z}_{\mathrm{E}} / L
\end{array}\right.
$$

Substituting Equations (7) and (8) into Equation (1), and comparing with Equation (2), the bulk coefficient for vapour yields

$$
\mathrm{C}_{\mathrm{E}}=\frac{\kappa^{2}}{\int_{\zeta_{\mathrm{m}_{1}}}^{\zeta_{\mathrm{m}_{2}}} \frac{\phi_{\mathrm{m}}}{\zeta} \mathrm{d} \zeta \int_{\zeta_{\mathrm{e}_{1}}}^{\zeta_{\mathrm{e}_{2}}} \frac{\phi_{\mathrm{e}}}{\zeta} \mathrm{d} \zeta} .
$$

The temperature flux $Q$ contained in $L$ is expressed with universal functions $\phi_{\mathrm{m}}$ and $\phi_{\mathrm{h}}$ and the difference in temperature at height $\mathrm{z}_{\mathrm{t}}$ and the surface $\left(T_{\mathrm{a}}-T_{\mathrm{s}}\right)$ :

$$
Q=\frac{\kappa U_{*}\left(T_{\mathrm{a}}-T_{\mathrm{s}}\right)}{\int_{\zeta_{\mathrm{m}_{1}}}^{\zeta_{\mathrm{m}_{2}}} \frac{\phi_{\mathrm{m}}}{\zeta} \mathrm{d} \zeta \int_{\zeta_{\mathrm{h}_{1}}}^{\zeta_{\mathrm{h}_{2}}} \frac{\phi_{\mathrm{h}}}{\zeta} \mathrm{d} \zeta}, \quad \text { where }\left\{\begin{array}{l}
\zeta_{\mathrm{h}_{2}}=\mathrm{z}_{\mathrm{t}} / L \\
\zeta_{\mathrm{h}_{1}}=\mathrm{z}_{\mathrm{T}} / L
\end{array},\right.
$$

where $\mathrm{z}_{\mathrm{T}}$ is the roughness length for temperature.

Various types of general functions were proposed (Yaglom, 1977), and those by Businger and others (1971) were applied with Kármán constant of 0.35 in this study, i.e.

and

$$
\phi_{\mathrm{m}}\left\{\begin{array}{lr}
=1+4.7 \zeta & (0 \leq \zeta \leq 1) \\
=(1-15 \zeta)^{-\frac{1}{4}} & (-2 \leq \zeta \leq 0)
\end{array}\right.
$$

$$
\phi_{\mathrm{e}}=\phi_{\mathrm{h}}\left\{\begin{array}{lr}
=0.74+4.7 \zeta & (0 \leq \zeta \leq 1) \\
=0.74(1-9 \zeta)^{-\frac{1}{2}} & (-2 \leq \zeta \leq 0)
\end{array}\right.
$$

In stable conditions, Equations (11) and (12) give the $\log$-linear approximation, and the value of 4.7 is equivalent to the coefficient $\alpha$. (This value is actually equivalent to 4.1 , if comparison to other works is necessary, because Businger and others (1971) proposed a Kármán constant of 0.35 .)

Andreas (1987) introduced a neutral stability interfacial sublayer over the rough or smooth surface in his model to predict bulk coefficients theoretically, and represents $z_{T} / z_{0}$ and $z_{E} / z_{0}$ as a function of roughness Reynolds number $R_{*} . R_{*}=u_{*} \mathrm{z}_{0} / v$, where $v$ is kinematic viscosity of the air. Andreas (1987) fitted them to the polynomials

$$
\left\{\begin{array}{rlr}
\ln \left(\mathrm{z}_{\mathrm{T}} / \mathrm{z}_{0}\right) & =0.317-0.565\left(\ln R_{*}\right) & \\
-0.183\left(\ln R_{*}\right)^{2} & \left(2.5 \leq R_{*}<1000\right) \\
\ln \left(\mathrm{z}_{\mathrm{T}} / \mathrm{z}_{0}\right)=0.149-0.550\left(\ln R_{*}\right) & \left(0.135<R_{*}<2.5\right) \\
\ln \left(\mathrm{z}_{\mathrm{T}} / \mathrm{z}_{0}\right)=1.250 & \left(R_{*} \leq 0.135\right)
\end{array}\right.
$$

and

$$
\left\{\begin{array}{rlrl}
\ln \left(\mathrm{z}_{\mathrm{E}} / \mathrm{z}_{0}\right) & =0.396-0.512\left(\ln R_{*}\right) & & \\
-0.180\left(\ln R_{*}\right)^{2} & & \left(2.5 \leq R_{*}<1000\right) \\
\ln \left(\mathrm{z}_{\mathrm{E}} / \mathrm{z}_{0}\right) & =0.351-0.628\left(\ln R_{*}\right) & & \left(0.135<R_{*}<2.5\right) \\
\ln \left(\mathrm{z}_{\mathrm{E}} / \mathrm{z}_{0}\right) & =1.610 & & \left(R_{*} \leq 0.135\right)
\end{array}\right.
$$

As Equations (5), (6), (10), (13) and (14) are simultaneously solvable, one can determine the bulk coefficient $\mathrm{C}_{\mathrm{E}}$ and estimate vapour flux $E$. In practical calculations using a computer, it is efficient to adopt iteration procedures. In the first step, $u_{*}$ and $Q$ are calculated for the case of neutral stability. In the iterations, $L$ and $\mathrm{z}_{\mathrm{T}}$ are recalculated with improved $U_{*}$ and $Q$. All these values converge in five or six iterations.

Figure 3 shows the vapour flux determined by the profile method from 12 to 29 July 1987 . Corresponding to the higher atmospheric vapour flux, condensation was dominant over this period. Figure 4 shows the vapour flux at the same measurement point determined by the lysimeter method from 15 to 23 August 1987. Strong evaporation in the daytime and slight evaporation at night were observed in this period, conversely. The 


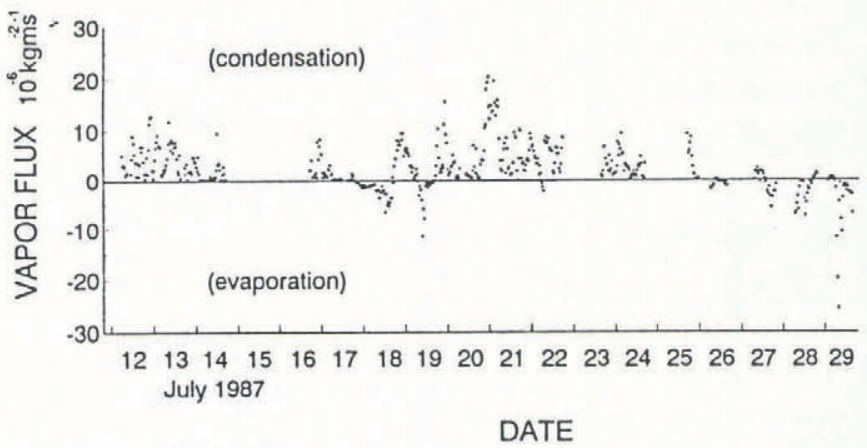

Fig. 3. The vapour flux from 12-29 July 1987, calculated with the bulk estimation.

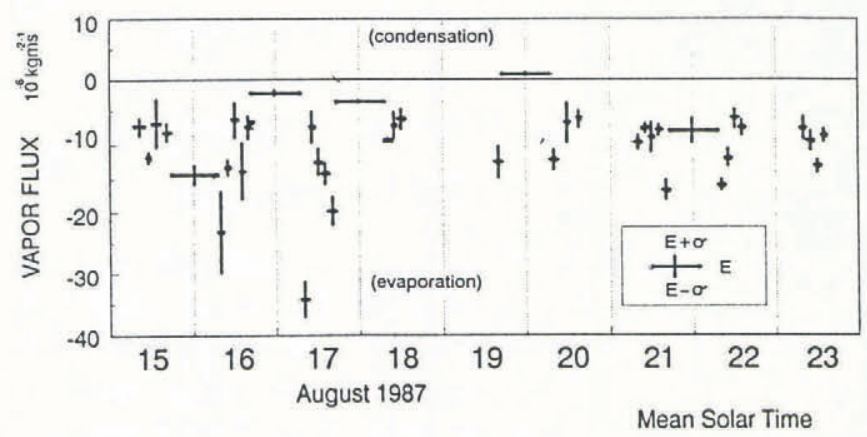

Fig. 4. The vapour flux from 15-23 August 1987, measured by the lysimeter method. Horizontal lines indicate the flux and exposing interval. The vertical lines show the standard deviations caused by averaging readings from six lysimeters.

dominant direction of vapour flux is not the same even at the same point and in the same season. This implies that one can put very little confidence in estimating a representative amount of evaporation by taking an average of the vapour flux measured for just a few tenday observation periods for continental-type glaciers. In order to extrapolate the vapour flux over the whole melting season, the relationship between daily meteorological data derived from the weather station and the integrated daily amount of evaporation was examined, and the following regression was established

$$
\bar{E}=0.28 \bar{U}\left(\bar{e}_{\mathrm{a}}-e_{0}\right),
$$

where

$\bar{E}$ : daily evaporation $\left[\mathrm{mm} \mathrm{d}^{-1}\right]$,

$\bar{U}$ : daily mean wind speed $\left[\mathrm{m} \mathrm{s}^{-1}\right]$,

$\bar{e}_{\mathrm{a}}$ : daily mean atmospheric vapour pressure [mbar],

$e_{0}$ : saturation vapour pressure of the melting ice, 6.11

[mbar].

In this regression, the data that are incomplete due to lack of measurements during the night have also contributed with the assumption that no evaporation occurs during the night. Figure 5 shows the relationship between integrated daily vapour flux $\bar{E}\left[\mathrm{~mm} \mathrm{~d}^{-1}\right]$ and the quantity calculated by the daily data. They are in good correlation $(r=0.90)$. In Figure 5 , data that are incomplete because of lack of measurement during the night are plotted in solid lines with black circles for

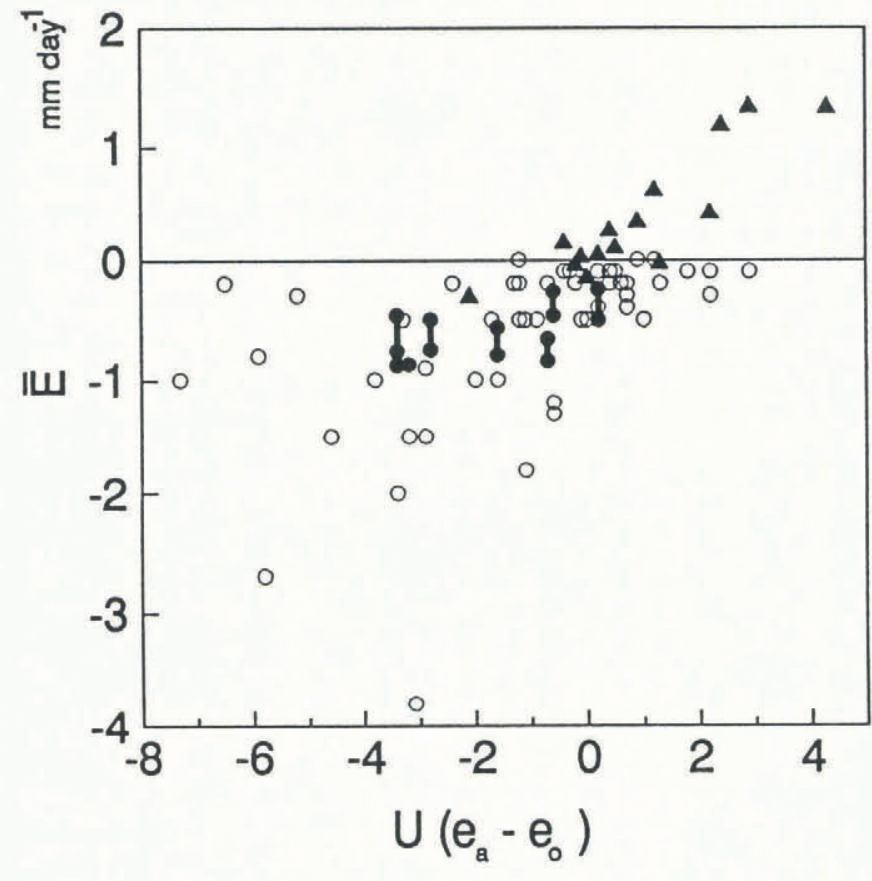

Fig. 5. The relationship between daily total vapour flux $\bar{E}$ $\left[\mathrm{mmd}^{-1}\right]$ and the product of the wind speed and the difference of vapour pressures. The results of bulk estimation and lysimeter measurements are indicated by black triangles and black circles, respectively. Incomplete data because of lack of measurement at night are plotted by solid lines with black circles for reference. Upper circles indicate those with the assumption that no evaporation occurs at night, and lower circles with the assumption that the vapour flux gradually changes from the last measurement of the day to the first measurement of the next day. For a reference, the data measured at the equilibrium line ( $3910 \mathrm{~m}$ a.s.l.) by Ohmura and others (1990) during the same summer are plotted with open circles.

reference. Upper circles indicate those with the assumption that no evaporation occurs during the night, and lower circles indicate the assumption that the vapour flux gradually changes from a day's last value to the first value of the next day. For a reference, the data measured at the equilibrium line $(3910 \mathrm{~m}$ a.s.l.) by Ohmura and others (1990) during the same summer are plotted with the open circles.

Using Equation (15), the estimated evaporation from 1 June to 30 August 1987 is $81 \mathrm{~mm}$. This value might have been influenced to some extent by the way that the melting season was determined because larger vapour fluxes are estimated at the beginning and end of the assumed melting season. Ohmura and others (1990) estimate the evaporation as $50 \mathrm{~mm}$ for 90 days of the melting period (June, July and August) on the same glacier, based on the aerodynamic gradient method from field observations in 1986 and 1987.

\section{NON-MELTING SEASON}

The lysimeter method and the energy-budget method which is based on the bulk estimation were applied to the 
non-melting season. Few measurements were made by lysimeter during the non-melting season because wind drift frequently occurred. To estimate the vapour flux, the following energy balance equation in the non-melting season is assumed:

$$
N R+H+\mathrm{L}_{2} E+C=0,
$$

where $N R, H$ and $C$ are net radiation, sensible heat flux and the heat conduction into the firn, respectively. $\mathrm{L}_{2}$ is latent heat for sublimation (2.835 $\left.\left[\mathrm{MJ} \mathrm{kg}^{-1}\right]\right)$. In this equation, $H$ is expressed in a similar form with $\mathrm{E}$,

$$
H=\mathrm{C}_{\mathrm{p}} \rho \mathrm{C}_{\mathrm{T}} U\left(T_{\mathrm{a}}-T_{\mathrm{s}}\right),
$$

where $\mathrm{C}_{\mathrm{p}}$ is the specific heat of air $\left(1005 \mathrm{~J} \mathrm{~kg}^{-1} \mathrm{~K}^{-1}\right)$. The term $C$ is set at zero in Equation (17) because the result of preliminary observation shows that it does not exceed $10 \%$. As Equation (17) can be regarded as an equation about the surface temperature $T_{\mathrm{s}}$ by substituting observed $N R, U, T_{\mathrm{a}}$ and $q_{\mathrm{a}}$, the vapour flux can be estimated by solving it. Figure 6 compares the vapour flux estimated by this method and that determined directly with lysimeters.

Figure 7 shows the evaporation rate from 6 to 21 April 1988 as an example. Strong evaporation was observed in the daytime. This evaporation is compensated by low intensity and long nocturnal condensation. The averaged vapour flux during autumn, winter and spring observervations are $0.21,0.13$ and $-0.25\left[\mathrm{~mm} \mathrm{~d}^{-1}\right]$, respectively. Therefore the total evaporation can be considered to be negligible during this season.

Although vapour flux is a function not only of $N R$ but also of $U, T_{\mathrm{a}}$ and $q_{\mathrm{a}}$ as mentioned before, $E$ is most strongly influenced by $N R$. Figure 8 shows their relationship. Fujii and Kusunoki (1982) observed intense evaporation at Mizuho Station, Antarctica, where the ice sheet never melted, in the 1977-78 summer. The maximum value, $0.92 \mathrm{~mm} \mathrm{~d}^{-1}$, was recorded on the day when the daily solar radiation was maximum. These facts

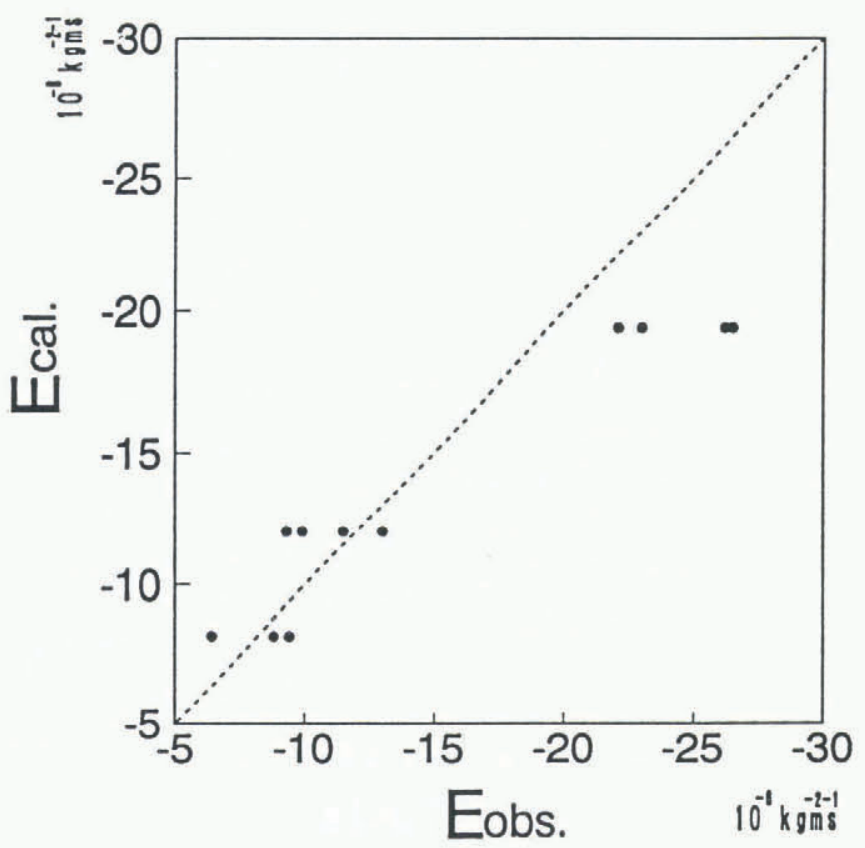

Fig. 6. The relationship between vapour flux measured by the lysimeter method and that estimated with the bulk formula.

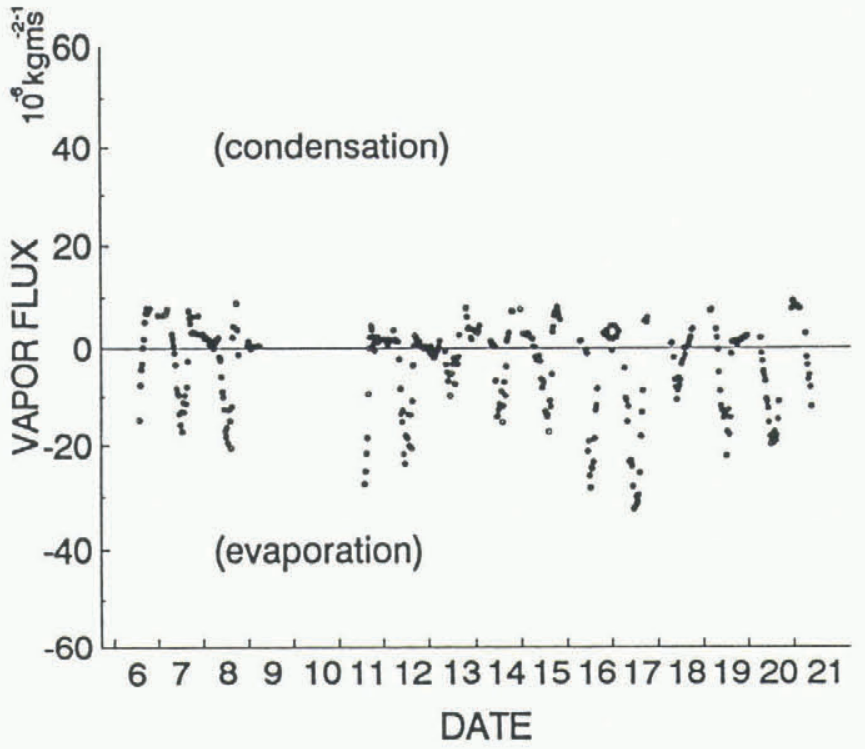

Fig. 7. The vapour flux from 6-21 April 1988 calculated by the bulk estimation based on energy balance.

suggest that evaporation in the non-melting season varies widely depending on aspect and angle of inclination because the contrast of global solar radiation on topography is clearer in this season.

\section{THE INFLUENCE OF EVAPORATION ON ABLATION}

The annual precipitation around the measurement site is determined as $650 \mathrm{~mm}$ (Yang and others, 1988). Assuming that the ablation and the annual precipitation were balanced on the glacier in this year, estimated annual evaporation of $81 \mathrm{~mm}$ is $12 \%$ of the ablation and consumes $54 \%$ of the energy which causes the ablation because ablation by evaporation occurs almost only during the melting period on this glacier. If atmospheric

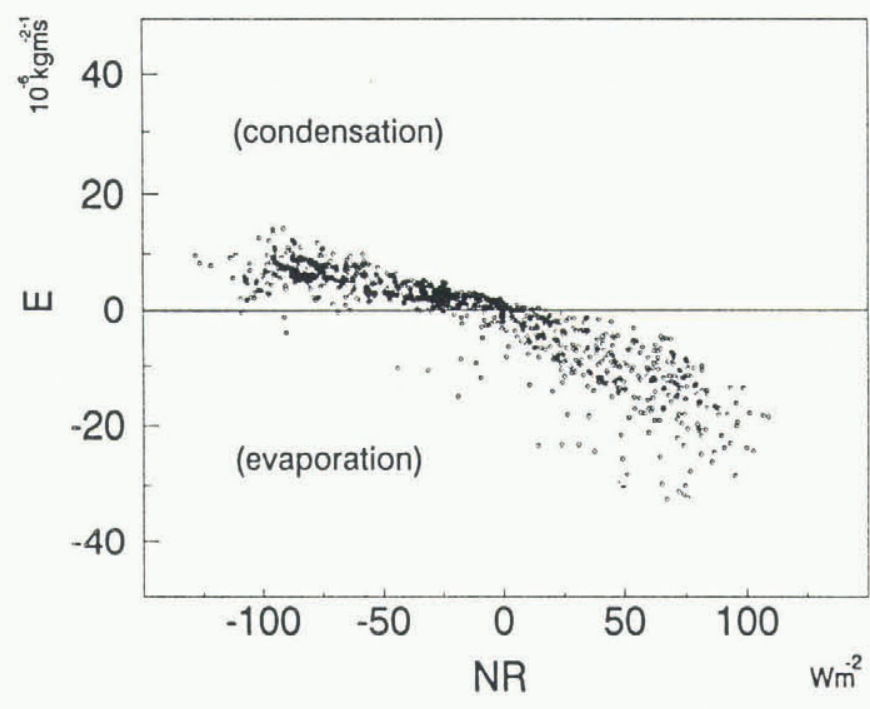

Fig. 8. The relationship between net radiation and estimated vapour flux in non-melting season. 
specific humidity increased and all of this energy were consumed by melting, as on maritime glaciers, the ablation would have increased up to $1260 \mathrm{~mm}$ without any change in air temperature. Therefore it can be said that, on this glacier, evaporation suppresses ablation by $48 \%$ compared with the condition in which there is no evaporation. Ohmura and others (1990) made the same consideration with their results, but only for the evaporation during the melt season, and estimated the. effect as $25 \%$.

\section{THE INFLUENCE OF GLIMATIC CHANGE ON ABLATION}

As the continental-type glaciers function as precious water resources, it is very important to investigate their response to climatic change. According to the record of average air temperature and atmospheric specific humidity in the northern hemisphere (Oort, 1983), annual fluctuations with amplitudes of $1{ }^{\circ} \mathrm{C}$ and $0.5 \mathrm{~g} \mathrm{~kg}^{-1}$ are not uncommon in recent decades. Therefore, the possible change in ablation $A$ (taken as positive value) $\left[\mathrm{mm} \mathrm{d}^{-1}\right]$ is evaluated using quantities

$$
0.5 \frac{\mathrm{d} A}{\mathrm{~d} T_{\mathrm{a}}} \quad \text { and } \quad 0.00025 \frac{\mathrm{d} A}{\mathrm{~d} q_{\mathrm{a}}}
$$

for the melting season as the indices of response of the glaciers.

The daily mass balance equation for the melting season is written

$$
\overline{N R}+\bar{H}+\mathrm{L}_{2} \bar{E}=\mathrm{L}_{1} M,
$$

where $\overline{N R}$ : daily net radiation $\left[\mathrm{J} \mathrm{m}^{-2} \mathrm{~d}^{-1}\right], \bar{H}$ : daily sensible heat flux $\left[\mathrm{J} \mathrm{m}^{-2} \mathrm{~d}^{-1}\right], M$ : daily melting (taken as positive value $\left[\mathrm{kg} \mathrm{m}^{-2} \mathrm{~d}^{-1}\right], \mathrm{L}_{1}$ : latent heat of fusion, 0.334 $\left[\mathrm{MJ} \mathrm{kg}^{-1}\right]$ and $A$ is expressed as

$$
A=M-\bar{E} .
$$

From Equations (18) and (19),

$$
A=\left\{\overline{N R}+\bar{H}+\left(\mathrm{L}_{2}-\mathrm{L}_{1}\right) \bar{E}\right\} / \mathrm{L}_{1} .
$$

Differentiating Equation (20), the following coefficients are obtained:

$$
\begin{aligned}
\frac{\mathrm{d} A}{\mathrm{~d} T_{\mathrm{a}}}= & \frac{\mathrm{C}_{\mathrm{p}} \rho U}{\mathrm{~L}_{1}}\left\{C_{\mathrm{H}}+\left(T_{\mathrm{a}}-T_{\mathrm{s}}\right) \frac{\mathrm{d} C_{\mathrm{H}}}{\mathrm{d} T_{\mathrm{a}}}\right. \\
& \left.+\frac{\mathrm{L}_{2}-\mathrm{L}_{1}}{\mathrm{C}_{\mathrm{p}}}\left(q_{\mathrm{a}}-q_{\mathrm{s}}\right) \frac{\mathrm{d} C_{\mathrm{E}}}{\mathrm{d} T_{\mathrm{a}}}\right\} \times 3600 \times 24
\end{aligned}
$$

and

$$
\frac{\mathrm{d} A}{\mathrm{~d} q_{\mathrm{a}}}=\rho U\left(\frac{\mathrm{L}_{2}}{\mathrm{~L}_{1}}-1\right) C_{\mathrm{E}} \times 3600 \times 24 .
$$

In this differentiation, the terms

$$
\frac{\mathrm{d} \overline{N R}}{\mathrm{~d} T_{\mathrm{a}}} \text { and } \quad \frac{\mathrm{d} \overline{N R}}{\mathrm{~d} q_{\mathrm{a}}}
$$

were not taken into account.

Figure 9 shows the feature

$$
0.5 \frac{\mathrm{d} A}{\mathrm{~d} T_{\mathrm{a}}}
$$

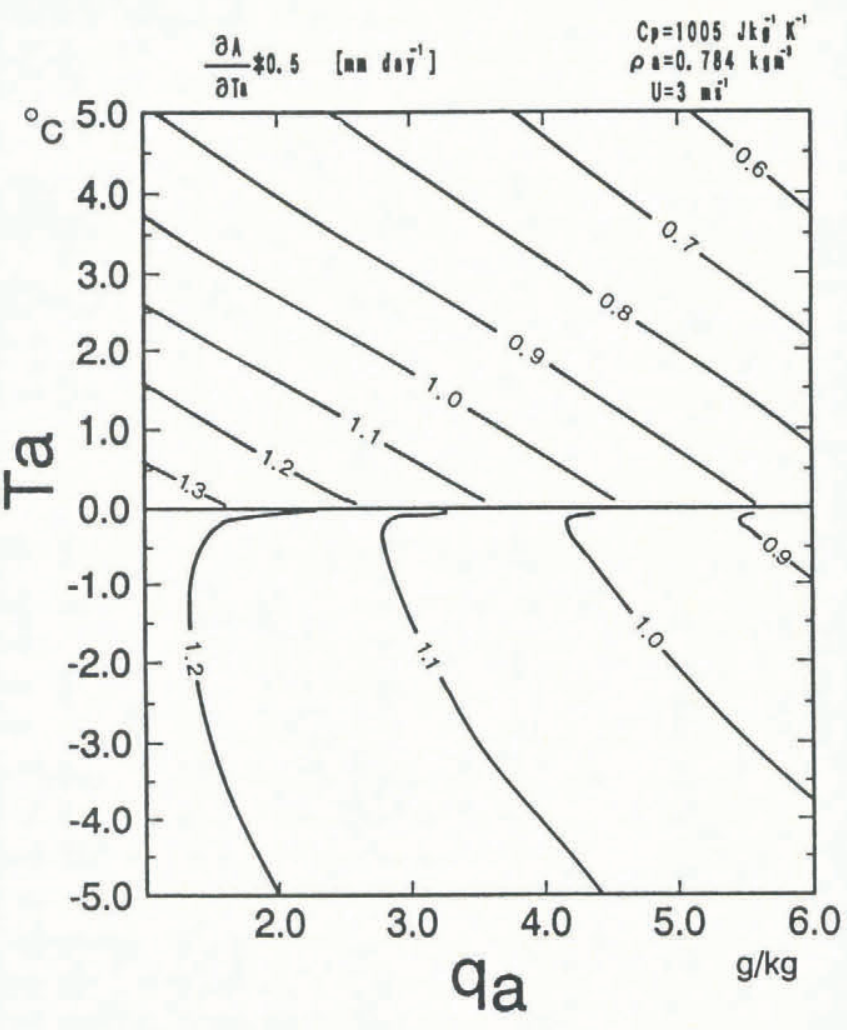

Fig. 9. Isopleths of possible ablation change when the air temperature changes by $0.5^{\circ} \mathrm{C}$ and the wind speed is $3 \mathrm{~m} \mathrm{~s}^{-1}$. Unit of the isopleth is $\left[\mathrm{mmd}^{-1}\right]$.

in the conditions around the measurement site. Though it corresponds to the difference in the atmospheric stability, the response is different between the area where the air temperature is above $0^{\circ} \mathrm{C}$ and where it is sub-zero. More response to temperature is caused in drier conditions. Figure 10 shows the feature of

$$
0.00025 \frac{\mathrm{d} A}{\mathrm{~d} q_{\mathrm{a}}}
$$

Glaciers in colder climates would be more sensitive to

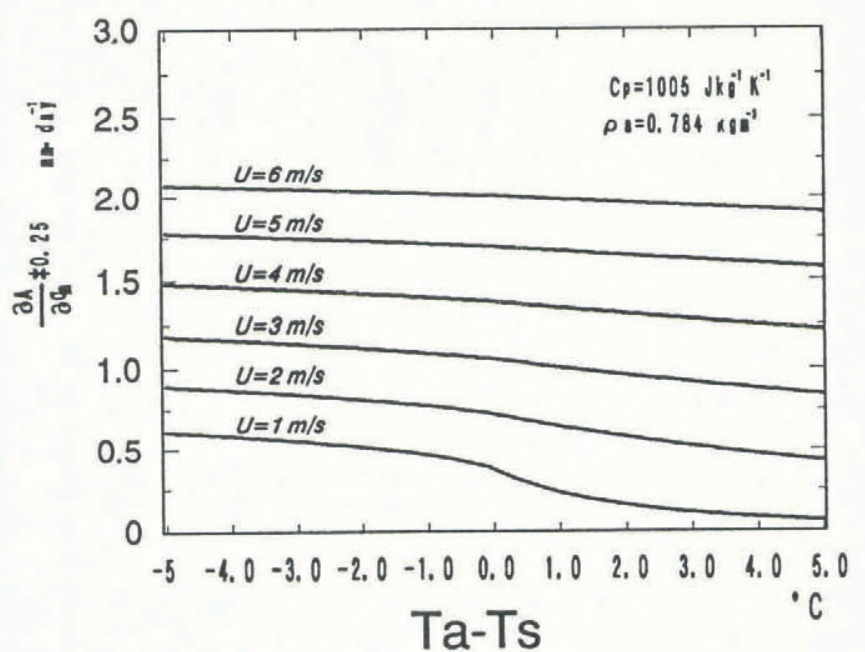

Fig. 10. The relationship of possible ablation change when mixing ratio changes by $0.25 \mathrm{~g} \mathrm{~kg}^{-1}$, and air temperature under various wind speeds. 


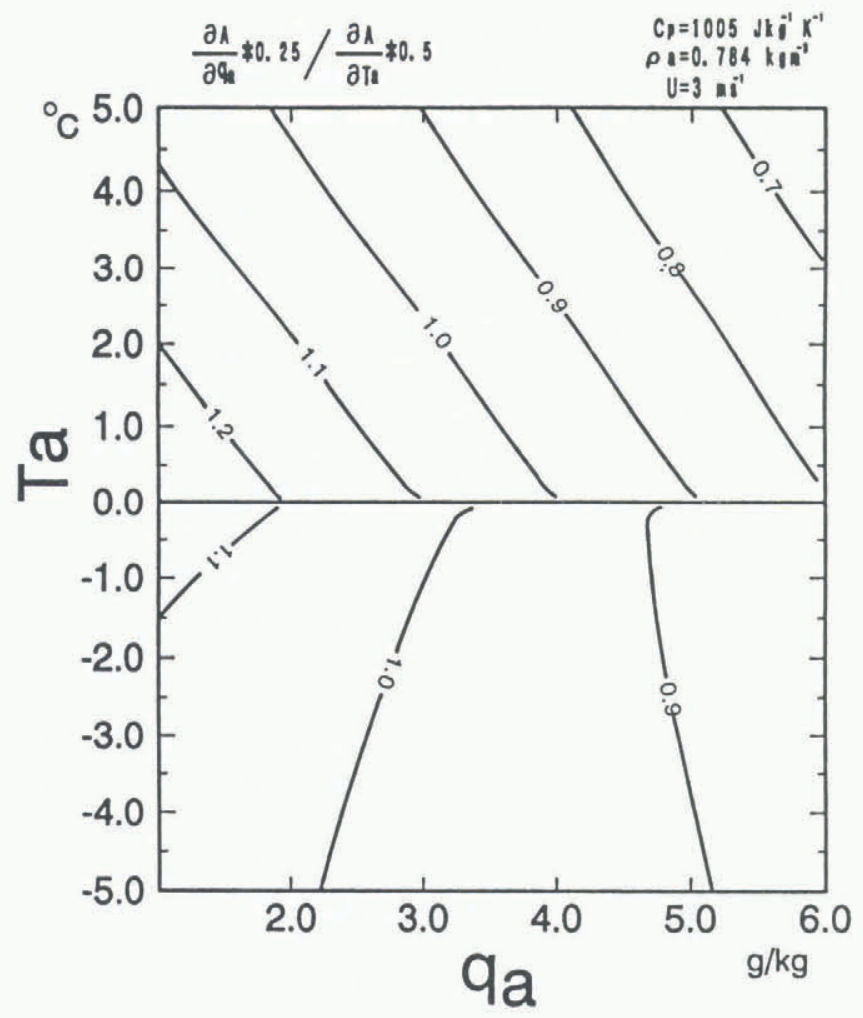

Fig. 11. The ratio of

$$
0.00025 \frac{\mathrm{d} A}{\mathrm{~d} q_{\mathrm{a}}} \quad \text { over } \quad 0.5 \frac{\mathrm{d} A}{\mathrm{~d} T_{\mathrm{a}}},
$$

with wind speed of $3 \mathrm{~m} \mathrm{~s}^{-1}$ and air pressure of $613 \mathrm{mbar}$. The larger the ratio is, the more sensitive a glacier is to a change in humidity rather than a change in air temperature.

humidity changes. The daily meteorological elements on the measurement site are estimated from the data at the weather station during the melting season and Equations (21) and (22) applied to them. Uniform wetting by $0.25 \mathrm{~g} \mathrm{~kg}^{-1}$ would increase ablation by $98 \mathrm{~mm}$ $\left(0.82 \mathrm{~mm} \mathrm{~d}^{-1}\right)$ while uniform warming by $0.5^{\circ} \mathrm{C}$ would increase ablation by $74 \mathrm{~mm}\left(0.61 \mathrm{~mm} \mathrm{~d}^{-1}\right)$. In the case of Glacier No. 1, larger ablation changes would be caused by change of humidity than by that of temperature with the indices. Similar calculations were made using hourly meteorological data derived on Chongce ice cap (5850 m a.s.l., $35^{\circ} 14^{\prime} \mathrm{N}, 81^{\circ} 07^{\prime} \mathrm{E}$ ) in the western Kunlun mountains, which is in a more arid and colder environment than is Glacier No. 1, from 26 July to 18 August 1987 (Ohata and others, 1989). On this glacier, warming would lead to a larger ablation change. Increase in specific humidity would cause $0.94 \mathrm{~mm} \mathrm{~d}^{-1}$ of ablation while warming would cause $1.27 \mathrm{~mm} \mathrm{~d}^{-1}$. Figure 11 , which shows the ratio of those two, explains this. Glaciers in a dry and cold climate have more sensitivity to change in temperature than to change in humidity by ratio.

\section{CONGLUSIONS}

Evaporation during the melting season suppresses ablation in continental-type glaciers through the process of heat balance. This is one of the important factors that enables glaciers to persist in arid regions where annual precipitation is several hundred $\mathrm{mm}$. Although the winter evaporation on the measurement site is very small, the possibility that the snow cover abrades intensely by evaporation on the south-facing slopes cannot be excluded, because evaporation in the non-melting season is controlled substantially by net radiation. Both the change in temperature and in humidity cause a larger change in ablation in the glaciers which are in colder and more arid climates. The influence of humidity change is important to glaciers in relatively humid and warm environments.

\section{ACKNOWLEDGEMENTS}

The author wishes to acknowledge the staff of Tien Shan Glaciological Station, Lanzhou Institute of Glaciology and Geocryology, for supporting the field observations.

\section{REFERENGES}

Ageta, Y., T. Ohata, K. Ikegami and K. Higuchi. 1980. Mass balance of Glacier AX010 in Shorong Himal, east Nepal during the summer monsoon season. F. Jpn. Soc. Snow Ice, 41, Special Issue, $34-41$.

Andreas, E. L. 1987. A theory for the scalar roughness and the scalar transfer coefficients over snow and sea ice. Boundary-Layer Meteorol., 38(1-2), 159-184.

Beaty, C. B. 1975. Sublimation or melting: observations from the White Mountains, California and Nevada, U.S.A. J. Glaciol., 14(71), 275-286.

Businger, J.A., J.C. Wyngaard, Y. Izumi and E. F. Bradley. 1971. Flux-profile relationships in the atmospheric surface layer. F. Atmos. Sci., 28, 181-189.

Croft, A. R. 1944. Evaporation from snow. Bull. Am. Meteorol. Soc., 25, 334-337.

Dyer, A.J. 1974. A review of flux-profile relationships. Boundary -Layer Meteorol., 7, 363-372.

Fujii, Y. and K. Kusunoki. 1982. The role of sublimation and condensation in the formation of ice sheet surface at Mizuho Station, Antarctica. 7. Geophys. Res., 87(C6), 4293-4300.

Golding, D. L. 1978. Calculated snowpack evaporation during chinooks along the eastern slopes of the Rocky Mountains in Alberta. 7. Appl. Meteorol., 17(11), 16471651.

Hay, J. E. and B. B. Fitzharris. 1988. A comparison of the energy-balance and bulk-aerodynamic approaches for estimating glacier melt. F. Glaciol., 34(117), 145-153.

Kaser, G. 1986. The role of evaporation from snow and ice in the mass balance of a glacier. Materialy Glyatsiologicheskikh Issledovaniy 57, 185-188.

Kojima, K., N. Ishikawa, H. Motoyama and Y. Yamada. 1985. Evaporation rate of snow at the surface of a snow cover - observations in Sapporo and Moshiri, Hokkaido. Low Temp. Sci., Ser. A 44, 49-62. [In Japanese with English summary.]

Kou Youguan, Xie Weirong, Xiao Shu and Li Wenzhong. 1982. The heat balance on glacial surfaces in China. Lanzhou Institute of Glaciology and Cryopedology. Academia Sinica. Memoirs 3, 91-101. [In Chinese with English abstract.] 
Lemmelä, R. and E. Kuusisto. 1974. Evaporationcondensation and snowmelt measurements in Finland. Nord. Hydrol., 5(1), 64-74.

Moore, R.D. 1983. On the use of bulk aerodynamic formulae over melting snow. Nord. Hydrol., 14(4), 193206.

Munro, D. S. 1989. Surface roughness and bulk heat transfer on a glacier: comparison with eddy correlation. F. Glaciol., 35(121), 343-348.

Munro, D. S. and J. A. Davies. 1978. On fitting the loglinear model to wind speed and temperature profiles over a melting glacier. Boundary-Layer Meteorol., 15, 423-437.

Ohata, T., S. Takahashi and Kang Xiangcheng. 1989. Meteorological conditions of the west Kunlun mountains in the summer of 1987. Bull. Glacier Res. 7, 67-76.

Ohmura, A., H. Lang, F. Blumer and D. Grebner, eds. 1990. Glacial climate research in the Tianshan. Research report on Project Glacier No. 1, 1985-1987. Zürcher Geogr. Schr. 38.

Ohno, H. 1988. Basic meteorological elements in boundary layer on Glacier No. 1, Tien Shan in melting and non-melting season. Annual report on the work at Tien Shan Glaciological Station. Lanzhou Institute of Glaciology and Geocryology. Academia Sinica. Memoirs 7, 23-44.

Ohno, H. 1989. An approach to estimate annual evaporation amount on "continental type" glaciers. Annual report on the work at Tien Shan Glaciological Station. Lanzhou Institute of Glaciology and Geocryology. Academia Sinica. Memoirs 8, 24-36.

Oort, A. H., ed. 1983. Global atmospheric circulation statistics 1958-1983. NOAA Prof. Pap. 14.

Shi, Y. and Z. Xie. 1964. The basic characteristics of existing glaciers in China. Acta Geographica Sinica, 30, 183-213.

Takahashi, S., T. Ohata and Xie Yingqin. 1989. Characteristics of heat and water fluxes on glacier and ground surfaces in the west Kunlun mountains. Bull. Glacier Res., 7, 89-98.

Takeuchi, K. and J. Kondo. 1981. The atmosphere near the ground.. In Ganpo, K. and T. Asai, eds. The atmospheric science course 1. Tokyo, Tokyo University Academic Press, 89-106. [In Japanese.]

Xie, W. and M. Cao. 1960. A preliminary observation of the snow surface evaporation on Glacier No. 1 at the head of Ürümqi River in Tien Shan mountains. In Chinese Academy of Science. Institute of Geography. Laboratory of Glaciology and Geocryology, ed. A study on the glaciers and hydrology in Ürümqi River basin of Tien Shan mountains. Beijing, Science Press, 70-73. [In Chinese.]

Yaglom, A. M. 1977. Comments on wind and temperature flux-profile relationship. Boundary-Layer Meteorol., 11, 89-102.

Yang, D., T. Jian, Y. Zhang and E. Kang. 1988. Analysis and correction of errors in precipitation measurement at the head of Ürümqi River, Tien Shan. 7. Glaciol. Geocryol., 10(4), 384-399. [In Chinese with English summary.]

The accuracy of references in the text and in this list is the responsiblity of the author/s, to whom queries should be addressed. 